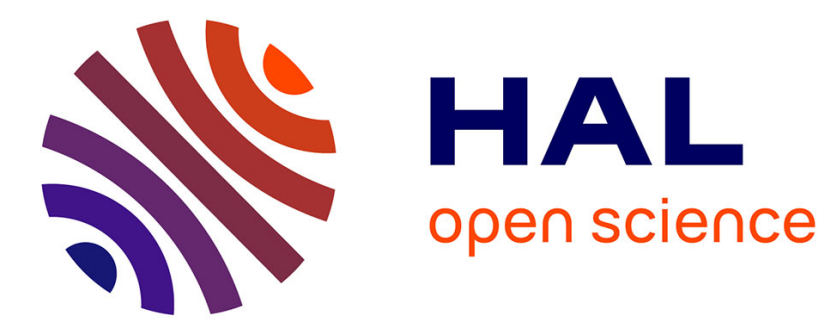

\title{
Power, Stability of Power, and Creativity
}

Daniel J. Sligte, Carsten K.W. de Dreu, Bernard A. Nijstad

\section{To cite this version:}

Daniel J. Sligte, Carsten K.W. de Dreu, Bernard A. Nijstad. Power, Stability of Power, and Creativity. Journal of Experimental Social Psychology, 2011, 10.1016/j.jesp.2011.03.009 peer-00995262

\section{HAL Id: peer-00995262 https://hal.science/peer-00995262}

Submitted on 23 May 2014

HAL is a multi-disciplinary open access archive for the deposit and dissemination of scientific research documents, whether they are published or not. The documents may come from teaching and research institutions in France or abroad, or from public or private research centers.
L'archive ouverte pluridisciplinaire HAL, est destinée au dépôt et à la diffusion de documents scientifiques de niveau recherche, publiés ou non, émanant des établissements d'enseignement et de recherche français ou étrangers, des laboratoires publics ou privés. 


\section{Accepted Manuscript}

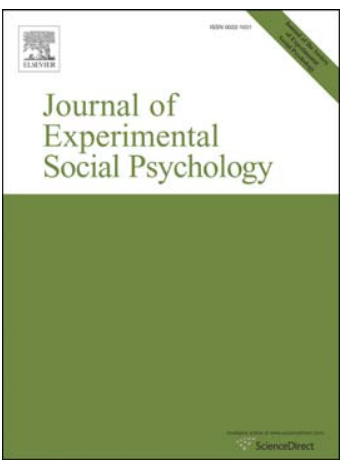

Power, Stability of Power, and Creativity

Daniel J. Sligte, Carsten K.W. de Dreu, Bernard A. Nijstad

PII: $\quad$ S0022-1031(11)00072-2

DOI: $\quad$ doi: $10.1016 /$ j.jesp.2011.03.009

Reference: $\quad$ YJESP 2640

To appear in: Journal of Experimental Social Psychology

Received date: 18 August 2010

Revised date: $\quad 2$ February 2011

Please cite this article as: Sligte, D.J., de Dreu, C.K.W. \& Nijstad, B.A., Power, Stability of Power, and Creativity, Journal of Experimental Social Psychology (2011), doi: 10.1016/j.jesp.2011.03.009

This is a PDF file of an unedited manuscript that has been accepted for publication. As a service to our customers we are providing this early version of the manuscript. The manuscript will undergo copyediting, typesetting, and review of the resulting proof before it is published in its final form. Please note that during the production process errors may be discovered which could affect the content, and all legal disclaimers that apply to the journal pertain. 
Power, Stability of Power, and Creativity

Daniel J. Sligte, Carsten K.W. de Dreu

University of Amsterdam

Bernard A. Nijstad

University of Groningen

\section{Author Note}

Daniel J. Sligte and Carsten K.W. De Dreu, Department of Psychology, University of Amsterdam, the Netherlands; Bernard A. Nijstad, Department of HRM and Organizational Behavior, University of Groningen, the Netherlands.

This research was supported by Grant NWO-400-06-098 from the Netherlands Organization for Scientific Research (NWO) awarded to Carsten de Dreu and Bernard Nijstad, and the FMG-UvA Research Priority Grant on Affect Regulation. The authors thank Hillie H. Aaldering for coding data in Experiment 2.

Address correspondence to Daniel J. Sligte, University of Amsterdam, Department of Psychology, Roetersstraat 15, 1018 WB Amsterdam, The Netherlands, Phone: +31 20 5256715, by fax: + 31 (0)20 6390531 or by email: d.j.sligte@uva.nl. 


\begin{abstract}
Power hierarchies are an essential aspect of social organization, create stability and social order, and provide individuals with incentives to climb the hierarchical ladder. Extending previous work on power and creativity, we put forward that this relationship critically depends on both the stability of the power hierarchy and the relevance of creative efforts to power. Across three experiments, we show that when power positions are unstable, low power individuals are more flexible thinkers, are less avoidant and process information more globally. Consequently, they achieve more creative insights, especially when being creative is relevant to power. As such, when the power hierarchy is unstable, those lacking power hold the power to creativity.
\end{abstract}

Keywords: creativity, power, global/local processing, avoidance, motivation 


\section{Power, Stability of Power, and Creativity}

Power hierarchies are so pervasive across both animal species and humans, that it appears a fundamental feature of social organization. Apart from behavioral manifestations ranging from abuse to benevolence and generosity (e.g., Handgraaf, Van Dijk, Vermunt, Wilke \& De Dreu, 2008), possessing power in and by itself fundamentally influences individuals' information-processing and behavioral tendencies (Fiske, 1993; Keltner, Gruenfeld, \& Anderson, 2003). However, mixed findings emerge for creative performance, with some studies demonstrating that power leads to higher creativity (Galinsky, Magee, Gruenfeld, Whitson \& Liljenquist, 2008; Smith \& Trope, 2006) while others point to an opposite pattern (Kuhl \& Kazen, 2008). In this article we show that the relationship between power and creativity critically depends on both the stability of the power hierarchy and the relevance of creative efforts to power. When the power hierarchy is unstable, individuals with low power employ a global and flexible processing style and become more creative especially when being creative is functional to climbing the ladder.

\section{Power leads to higher creativity}

Power refers to the ability to influence others (Bacharach \& Lawler, 1981; Kelley \& Thibaut, 1978), and derives from a variety of power bases, such as someone's position in the hierarchy within a group or organization, or the possession of valuable resources, such as knowledge and expertise (French \& Raven, 1958; Lee \& Tiedens, 2001; Podsakoff \& Schriescheim, 1985; Yukl \& Falbe, 1991). Power hierarchies create social order and stability, and because having power yields control over one's environment and resources to survive and prosper, individuals are motivated to climb the hierarchical ladder.

Recent work in psychological science revealed that power has metamorphic effects on power holders (Fiske, 1993; Keltner, Gruenfeld, \& Anderson, 2003). Powerful individuals process information more abstractly and flexibly (Guinote, 2007; Smith \& Trope, 2006; 
Förster, 2009), use less diagnostic and more confirmatory strategies (De Dreu \& Van Kleef, 2004; Leyens, Dardenne, \& Fiske, 1998), and are less influenced by situational cues (Galinsky et al., 2008) and emotional expressions of others (Van Kleef, De Dreu, Pietroni \& Manstead, 2006). Behaviorally, the powerful take more risks in their decisions (Anderson \& Galinsky, 2006), they act more swiftly when facing an annoying obstacle (Galinsky, Gruenfeld \& Magee, 2003) and behave more in a goal-consistent manner (Guinote, 2007).

The key explanation for these effects proceeds on the basis of the assumption that powerful individuals think and act so as to maintain and increase power (Bruins \& Wilke, 1992; Maner, Gaillot, Butz \& Peruche, 2003; Maslow, 1937); powerless individuals, in contrast, think and act to protect against possible threat (in part coming from powerful others). As a result, having power leads to approach motivation with its concomitant global attentional focus (Förster, Friedman, Özelsel \& Denzler, 2006). Having power frees one from influence from others, and leads to feelings of safety and security (Friedman \& Förster, 2010). Lacking power, in contrast, triggers avoidance motivation, a focus on potential losses, and a narrow attentional focus (Keltner et al., 2003; Förster et al., 2006). Because both approach motivation (Baas, De Dreu, \& Nijstad, 2008; Friedman \& Förster, 2001, 2002, 2005) and global attentional focus (De Dreu, Nijstad, \& Baas, 2011; Förster \& Higgins, 2005; Förster, Liberman \& Friedman, 2005) promote cognitive flexibility, set-breaking and abstract thinking, it follows that powerful individuals also are more creative than their powerless counterparts (Forster, 2009; Galinksy et al., 2008; Smith \& Trope, 2006; but see Kuhl \& Kazen, 2008).

An interesting implication of this socio-functional perspective on power and cognition is that cognitive processes operate in the service of the underlying motivation to maintain and increase power. Put differently, the tendency among powerful individuals to think globally and display cognitive flexibility should be particularly pronounced when doing so serves the 
goal of maintaining or expanding power. When creative performance is functionally relevant to one's power position, we would thus expect more creativity than when creative performance is functionally irrelevant. An example of such functionally relevant creativity is when a middle-manager of a company is facing decreasing revenues, and new and creative ideas are needed to turn the situation around. By solving the company's problems in creative ways (e.g., through introducing new products or services, or by increasing market share through creative marketing) a manager can show high competence and may as a consequence be promoted to a higher position.

Psychological science provides some support for the idea that creative performance can be boosted when it is functionally relevant. Recent work shows that in addition to costs and risk, being original and creative accrues desirable benefits. For example, being creative increases individuals' attractiveness as a potential mate (Griskevicius, Cialdini \& Kenrick, 2006; Miller, 2000), and helps individuals winning a conflict (De Dreu \& Nijstad, 2008).

\section{Unstable power and creativity}

A socio-functional perspective on power further implies that individual power is not a given and that power is not necessarily a stable feature of the situation within which the individual operates. Rather, power positions may change: powerful individuals may become powerless, and powerless people may become powerful (Tajfel, 1984). In an unstable power hierarchy, the powerful can be expected to be motivated to maintain their privileged position (Tetlock, 1981), especially when their position is directly disputed. They may become threatoriented (Scheepers \& Ellemers, 2008), leading the powerful to become risk averse and more focused on preventing that someone takes over (some of their) privileges (Lammers, Galinsky, Gordijn \& Otten, 2008; Maner et al., 2003). Moreover, subtle cues signaling a potentially dangerous environment may lead to attentional focusing and less creativity (Friedman \& Förster, 2010). When power becomes unstable, the intricate link between being 
powerful, approach motivation and global attentional focus may thus break down. Those having and valuing high power may become afraid of losing power, and powerless individuals face the prospect of moving up the hierarchy, thus realizing greater safety (Higgins, 1997). Those with low power may therefore become approach motivated and beget a broad attentional focus (Friedman \& Förster, 2010; see also Kuhl \& Kazen, 2008).

Indirect evidence for our thesis that the stability of the power hierarchy matters comes from work manipulating the legitimacy of the individual's power position. When the power position is legitimate, powerful individuals are more action-oriented, use more flexible strategies to attain their goals and are more persistent in the face of obstacles than powerless individuals. When the power position is illegitimate, however, the pattern reverses and powerless individuals display greater action-orientation and cognitive flexibility than powerful individuals (Willis, Guinote \& Rodríguez-Bailón, 2009). Illegitimacy may undermine the perceived stability of the power hierarchy, and increases the likelihood of losing power (among powerful individuals) and gaining power (among powerless individuals).

Accordingly, we expected that when the power hierarchy is stable, powerful individuals have stronger approach motivation, engage in more global rather than local processing, and therefore are more creative than powerless individuals. We furthermore hypothesized that when the power hierarchy is unstable, these general tendencies reverse: powerful individuals facing the possibility of power loss become avoidance oriented, engage in more local rather than global processing and become relatively more rigid and less creative in their thinking than powerless individuals facing the possibility of power gains. We finally hypothesized that the latter tendency for powerless individuals to be more creative than powerful individuals under unstable conditions is particularly pronounced when creative performance is functionally relevant, rather than irrelevant, to the goal of gaining power. 
We tested these predictions in three experiments in which power roles were assigned and stability of power and functionality of creativity were manipulated. Experiment 1 was a first test of our predictions using a creativity test of conceptual insight. Experiment 2, a brainstorm study, focused on unstable power positions and was designed to test if low power individuals would be cognitively more flexible and consequently more creative especially when creativity was functionally relevant. Experiment 3 was designed to uncover the mediating process: it assessed whether it is approach (vs. avoidance) motivation, global (vs. local) attentional focus, or some combination of the two that explains why powerless individuals in unstable hierarchies are more creative than powerful individuals.

\section{Experiment 1}

Experiment 1 was designed to test if under stable power high power individuals would be more creative than low power individuals especially when creativity was functionally relevant to power. Moreover, we tested if these effects would reverse under unstable power, making low power individual more creative than high power individuals. Our measure of creativity was the Remote Associates Test (RAT; Mednick, 1962), a test in which people have to break set to find one word that relates to three other words. The RAT benefits from flat associative hierarchies and seeing interrelationships between concepts, which is generally beneficial to creativity.

\section{Method}

\section{Design and participants}

One hundred thirty nine students (age $M=21.3, S D=4.2 ; 51$ male) participated for $€ 7$ (approximately U.S. \$9.50) or partial course credit. Participants were randomly assigned to the conditions of a 2 (power position: high vs. low) x 2 (stability of power position: stable vs. unstable) x 2 (functionality: relevant vs. not relevant) between-participants factorial design, with creative insight performance as the dependent variable. 


\section{Procedures and manipulations}

Upon arrival at the laboratory, participants were seated in front of a computer with keyboard. Instructions and measures were given on the computer. Participants were told that they would engage in a task in which they had to work with another participant. Power position was manipulated by assigning participants randomly to the position of high or low power. Participants were told that the high power individual would be in charge of the division of labour, monitor progress and assess performance of the low power individual after completion of the joint task (see e.g., De Dreu \& Van Kleef, 2004). The rewards of the low power individual would be contingent on this assessment. Stability of power position was manipulated by telling participants that power positions were assigned randomly and that power positions would remain unchanged during the experiment (stable power condition), or that power positions might be switched later on in the experiment (unstable power condition). Before participants did the joint task, they were asked to do a task that putatively measured verbal intelligence, the Remote Associates Test (RAT; see under "Dependent measures"). Relevance was manipulated by telling participants (or not) that research had shown that verbal intelligence was relevant to effective functioning in high power positions. We did not directly state, however, that performance on the RAT could change the power hierarchy. After completing the RAT, participants were informed that the experiment was over, were debriefed, paid and dismissed.

Dependent measures. The RAT consisted of 10 moderately difficult items (see De Dreu et al., 2011; Harkins, 2006; Isen, Daubman, \& Nowicki, 1987) in which participants have to find the correct word that connects three other words (e.g. black-beans-break -> coffee). We coded the number of correctly solved RAT-items (ranging from 0 to 10). We also included manipulation checks for power, stability and functionality. For the power manipulation, participants were asked to tick the correct box for the question: "In the joint 
task, I will have:". The options were: $1=$ low power; 2 = high power; $3=$ don't know. For the stability manipulation, participants were asked to tick the correct box for the question "The power differences in the joint task:". The options were: 1 = can change; 2 = cannot change; 3 = don't know). Finally, to check our manipulation of relevance, participants answered on a 5-point Likert scale ( $1=$ not at all, 5 = very): "How relevant is verbal intelligence to effective functioning in high power positions?".

\section{Results and Discussion}

Manipulation checks. All participants correctly answered the manipulation check on power. All but nine participants correctly answered the manipulation check on stability of power. Excluding these participants from analyses did not change the results. Participants in the functionally relevant condition $(M=4.74, S D=.75)$ indicated verbal intelligence was more important to effective functioning in high power positions than in the functionally irrelevant condition $(M=3.09, S D=1.36), F(1,144)=50.78, p<.01$, partial $\eta^{2}=.26$.

Creative performance. We submitted the number of correctly solved RAT-items to a 2 (Power Stability) x 2 (Power Position) x 2 (Functionality of Creativity) Analysis of Variance (ANOVA). Results showed a significant two-way interaction among power position and power stability, $F(1,138)=7.05, p<.05$, partial $\eta^{2}=.05$. Simple effects analyses showed that when power positions were stable, individuals with high power tended to outperform individuals with low power $(M=4.74, S D=1.94$ vs. $M=3.92, S D=1.86, F(1$, $138)=3.18, p<.10)$ while the opposite trend emerged when positions were unstable $(M=$ $3.79, S D=2.05$ vs. $M=4.85, S D=1.87 ; F(1,138)=3.53, p<.10)$.

More importantly, this effect was qualified by a significant three-way interaction among power, stability and relevance, $F(1,138)=3.95, p<.05$, partial $\eta^{2}=.03$. Analyses showed that when creative performance was functionally irrelevant to power, no significant effect occurred, $F(1,138)<1, p=.64$, and creative performance was generally low (see 
Figure 1). When creative performance was functionally relevant to power, there was a significant two-way interaction among power position and power stability, $F(1,138)=10.47$, $p<.01$. As predicted, when creative performance was relevant and positions were stable, individuals with high power outperformed individuals with low power, $F(1,138)=6.19, p$ $<.05$. The opposite pattern occurred when positions were unstable, $F(1,138)=4.28, p<$. 05, thus supporting our predictions.

Taken together, results support the prediction that under stable power, high power individuals are more creative than low power individuals. Under unstable power, however, low power individuals are more creative, but only when creativity was relevant to power. This adds to the important role the relevance of creative endeavors seems to play. Experiment 2 was designed to replicate these findings with a different creativity task.

\section{Experiment 2}

In Experiment 2 we used an idea generation task to test our hypothesis that under unstable power, people low in power are more creative than those high in power, especially when creative efforts are relevant to one's power position. Because the most interesting results occurred in the unstable power position, where - unlike in previous work - the low power individuals were more creative than the high power individuals, we focused on unstable power conditions in this experiment. More than creative insight tasks, an idea generation task allows one to examine an important predictor of creativity, namely cognitive flexibility. This was achieved by coding ideas into semantic categories, the idea being that cognitive flexibility shows up in the use of many rather than few different categories of ideas (e.g., Guilford, 1950; Torrance, 1966; also see De Dreu et al., 2008; Nijstad, De Dreu, Rietzschel, \& Baas, 2010).

In addition to cognitive flexibility, we also assessed the number of ideas generated (fluency) and the average originality of ideas. Using these different indices of performance 
allows one to gain some insight into the cognitive processes that underlie our effects. The number of ideas (fluency) is generally highly dependent on effort, but this is less true for average originality (although fluency and originality may be positively correlated; see e.g., De Dreu et al., 2008; Diehl \& Stroebe, 1987; Nijstad et al., 2010; Osborn, 1953) and flexibility. We expect that power position and the relevance of creativity not only affects effort, but also one's motivational orientation (approach vs. avoidance) and attentional focus (broad vs. narrow). Therefore, we predict that -given unstable power- cognitive flexibility would be higher for people low in power than for people high in power, especially when creativity is relevant to power. Furthermore, analogous effects on fluency and originality are expected.

\section{Method}

\section{Design and participants}

Participants were 55 undergraduate students (age $M=21.8, S D=5.0 ; 17$ male) at the University of Amsterdam and they received either $€ 7$ (approximately U.S. \$9.50) or partial course credit. The design was a 2 (power position: high vs. low) x 2 (brainstorming relevant vs. not relevant) factorial design. All power positions were unstable. Dependent measures were flexibility, creative fluency and originality of generated ideas.

\section{Procedures and manipulations}

These were largely the same as in Experiment 1. Power and relevance were manipulated as before. Participants then proceeded with a four-minute brainstorming task about ways to protect and improve the environment. They were told that they had to come up with as many ideas as possible, refraining from self-criticism and evaluation. Additionally, we told them that they did not have to elaborate on the ideas but to describe them in catchwords. Thereafter participants filled out manipulation checks and were debriefed, paid and dismissed. 
Dependent measures. To get at cognitive flexibility, we counted the number of cognitive categories participants drew their ideas from. These 10 categories were imposed on the data and used to guide the coding. The 10 categories relate to the goal of intervention to protect and improve the environment (e.g. reducing pollution, improving use of energy sources), adapted from Nijstad, Stroebe, and Lodewijkx (2003). A second rater coded a random subset of the ideas $(N=340,30 \%)$ into one of the ten categories with good agreement (Cohen's $\kappa=.79)$. The number of non-redundant ideas was counted per participant to come to a measure of creative fluency. Finally, originality was coded by two independent raters on a 5-point scale ( $1=$ not original, $5=$ highly original; see Rietzschel, Nijstad \& Stroebe, 2006). Interrater agreement was satisfactory following criteria of Cicchetti and Sparrow (1981; intraclass correlation, ICC $(2)=.71)$ and we used the aggregation across raters as an indicator of originality.

\section{Results and Discussion}

\section{Manipulation checks}

All but two participants correctly answered the manipulation checks on power and stability. Excluding these participants did not change the results. Participants in the functionally relevant condition $(M=4.75, S D=.52)$ indicated verbal intelligence was more important to effective functioning in high power positions than in the functionally irrelevant condition $(M=4.07, S D=.86), F(1,54)=14.13, p<.01$, partial $\eta^{2}=.21$.

\section{Flexibility, originality and fluency}

We tested the effects of power and relevance on flexibility by submitting flexibility to a 2 (Power position) x 2 (Functionality of Creativity) ANOVA. Recall that all power positions were unstable. Results showed a significant two-way interaction, $F(1,54)=7.32, p$ $<.01$, partial $\eta^{2}=.13$. As shown in Figure 2, analyses of simple effects showed that low power individuals were more flexible $(M=3.79, S D=1.25)$ than high power individuals $(M=$ 
$2.36, S D=1.55)$ but only when the brainstorming task was relevant to power, $F(1,54)=$ $6.25, p<.05$. This is in line with our predictions. We also tested the effects of power and relevance on originality and fluency with a $2 \times 2$ ANOVA. The two-way interaction among power and relevance on originality was not significant, $F(1,54)<1, p=.34$. The two-way interaction on fluency was also not significant, $F(1,54)<1, p=.49$.

Taken together, results provide a conceptual replication of our earlier finding. Specifically, under unstable power, low power individuals displayed higher cognitive flexibility (but not greater originality). That we did find predicted effects on cognitive flexibility, but not on originality may be due greater measurement error in the ratings of originality and to the fact that average ratings of originality were rather low overall (i.e., a floor effect; $M=1.80, S D=0.50)$. Future research is needed to clarify this.

\section{Experiment 3}

Experiment 3 was designed to further insight into the underlying processes responsible for the effects of power position and functionality of creativity on creative insight performance (see Experiment 1) and cognitive flexibility (see Experiment 2). At the outset, we identified two such mechanisms. One possibility is that under unstable power conditions, those with low power adopt an approach motivation. In fact, when power is illegitimate, low power individuals become more approach and less avoidant motivated, have greater risk preferences (Lammers et al., 2008), are more action-oriented, persistent and more flexible in attaining their goals (Willis et al, 2009). It is thus conceivable that -when power differences are unstable- low power individuals become more approach and less avoidant motivated than high power individuals and that this leads them to become more creative. A second possibility is that under unstable power, low power individuals beget more of a global attentional focus, think more abstractly and therefore are more creative than those high in power. Following Construal Level Theory (Trope \& Liberman, 2003), high power people - 
more than those low in power- tend to adopt a global helicopter view of their environment and focus on the gist of a situation rather than losing themselves in details (Smith \& Trope, 2006). However, when power differences are unstable, this pattern may reverse causing low power individuals to focus on the big picture to be able to seize power. Abstract thinking and a global focus generally benefit creativity (Förster, Friedman \& Liberman, 2004).

We designed Experiment 3 to disentangle the two possible mediating mechanisms. We included a word completion task (Roskes, De Dreu \& Nijstad, 2010) to measure approach vs. avoidance motivation and the Navon task (Navon, 1977) to assess global vs. local attentional focus. To measure creativity, we used the Snowy Pictures Test (SPT; Ekstrom, French, Harman \& Dermen, 1976). The SPT consists of 24 pictures hidden in a complex pattern of visual noise and measures perceptual insight. To get at the correct solution, people typically have to restructure information to discover the solution (Schooler \& Melcher, 1995), and such restructuring also benefits creativity.

\section{Method}

\section{Design and participants}

Fifty four undergraduate students (21 males) at the University of Amsterdam participated for either $€ 7$ (approximately U.S. \$9.50) or partial course credit. The design was a 2 × 2 factorial design, with power position (high vs. low power) and relevance (yes vs. no) as between-subjects factors. All power positions, again, were unstable. Participants were randomly assigned to experimental conditions.

\section{Procedures and manipulations}

Procedures and manipulations were largely the same as in Experiment 2. We manipulated relevance of creativity by making the SPT relevant to power or not. When the SPT was relevant, participants were informed that to function effectively in power positions, it is important to have well-developed spatial abilities. When starting the SPT, participants 
were informed that they were about to do a test that measured spatial ability and reminded of the importance of this quality for functioning well in power positions. After instructions and assignment to experimental conditions, participants were asked to do two supposedly unrelated tasks: the Navon task (Navon, 1977) and a Word Completion Task (Roskes et al., 2010). Participants were then asked to do the SPT. The items in this task followed in random order. Once participants had finished the SPT, they were informed that the experiment was over and the joint task would not take place. They filled out manipulation checks and were debriefed, paid and dismissed.

Dependent measures. We coded the number of correct solutions to the SPT-items (range between 0 and 24). To measure global vs. local processing, we used the Navon task (Navon, 1978). In this task, participants are asked to respond as quickly as possible to letters shown on screen. These letters are large letters composed of small letters that always differed from the large letters, for example an A made up of small T's. Participants did one hundred trials. The task was to press a key as fast as possible when they saw a specific letter. In half of the trials these were small letters composing a large letter, in the other half of the trials this was a large letter composed of small letters. Only correct trials were included in the analyses. After an outlier analysis, the average reaction time (in seconds) on the large and small letters was computed. We subsequently computed a composite measure by subtracting the reaction time on the large letters from the small letters. A positive score on this measure thus evidenced a global processing style (seeing the large letters faster than the small letters), a negative score a local processing style.

To measure approach vs. avoidance motivation, we used a Word Completion Task. Participants were presented with words from which one or two letters were missing. They were asked to complete these words. Seven of these words could be completed relating to avoidance (e.g. VERM...DEN -> VERMIJDEN; to avoid) or neutral (VERMOEDEN; to 
suspect), seven could be completed relating to approach (BEREI.EN -> BEREIKEN; to achieve) or neutral (BEREIDEN; to prepare). We coded the number of words completed as approach or avoidance.

\section{Results and discussion}

\section{Manipulation checks}

All participants answered the manipulation check on power correctly. Participants in the functionally relevant condition $(M=4.37, S D=1.01)$ indicated verbal intelligence was more important to effective functioning in high power positions than in the functionally irrelevant condition $(M=2.81, S D=1.49), F(1,53)=19.55, p<.01$, partial $\eta^{2}=.26$.

\section{Creative insight}

We submitted the scores on the SPT to a 2 (Power position) X 2 (functionality of creativity) ANOVA. We found an interaction effect among position and functionality, $F$ (1, $53)=4.03, p<.05$, partial $\eta^{2}=.08$. As shown in Figure 3 and Table 1, analyses of simple effects showed that low power individuals had higher performance on the SPT than high power individuals when the SPT was functional to position $(M=10.79, S D=3.02$ vs. $M=$ $7.85, S D=2.91, F(1,53)=6.86, p<.05)$ while there were no differences when the SPT was nonfunctional $(M=9.00, S D=3.21$ vs. $M=9.29, S D=2.64 ; F(1,53)=.06, p>.05)$, lending additional support to our predictions.

\section{Processing style and approach/ avoidance}

There was a significant two-way interaction among position and functionality on performance on the Navon task, $F(1,53)=5.87, p<.05$, partial $\eta^{2}=.12$. Simple effects analyses showed that low power individuals were more globally focused than high power individuals when the SPT was functional to their position $(M=.027, S D=.064$ vs. $M=-.017$, $S D=.054 ; F(1,53)=4.99, p<.05)$ while no differences were found when the SPT was 
nonfunctional $(M=-.009, S D=.034$ vs. $M=.015, S D=.050 ; F(1,53)=1.50, p>.10)$, see Table 1.

No significant interactions were found on the approach measure. We did, however, find a significant interaction among position and functionality on the avoidance measure, $F$ $(1,53)=6.69, p<.05$, partial $\eta^{2}=.12$. Inspection of simple effects showed that low power individuals were less avoidant than high power individuals when the SPT was functional $(M=$ $1.86, S D=.77$ vs. $M=2.85, S D=1.21 ; F(1,53)=5.64, p<.05)$ while no differences were found when the SPT was nonfunctional $(M=2.77, S D=1.24$ vs. $M=2.21, S D=1.12 ; F(1$, 53) $=1.72, p>.10$ ), see Table 1 . Moreover, processing style and the avoidance measure correlated negatively $(r=-.34, p<.05)$.

\section{Mediation of processing style on creative insight}

We conducted a hierarchical regression analysis to test if the effects of position and functionality on performance on the SPT were mediated by either processing style (Navon) or avoidance (Word Completion). We first entered the main effects of dummy coded independent variables position and functionality, then the interaction effect of position $\mathrm{x}$ functionality, and finally scores on the Navon or Word Completion Task. The Word Completion Task did not mediate the effects on the SPT. Scores on the Navon significantly predicted SPT-performance, $B=2.40, t=3.35, p<.01$. And, when controlled for the effect of the scores on the Navon task, the interaction effect among position and functionality on the SPT disappeared, $B=1.84, t=1.15, p=.26$. A Sobel test (see Sobel, 1986) showed that the mediation of processing style was significant, $Z=1.99, p<.05$ (see Figure 4).

In short, low power individuals outperformed high power individuals on creative insight when doing was functional to position because they had a global processing style. The reason for the fact that processing style and not avoidance motivation mediated the effects of unstable power on creativity may be twofold. First, processing style is a more proximate 
predictor of behavior, as it relates to the scope of perceptual and conceptual attention. In fact, approach motivation may lead to global processing (Förster et al., 2006). Second, small differences in the reliability of measurement may have consequences for the ability to show mediation. Our measure of processing style was very accurate, using a measure of reaction times accurate at the level of milliseconds. Our measure of avoidance motivation may have been less reliable, and this may explain the weaker effects for this variable.

\section{General discussion}

The current research tested the hypothesis that under stable power, high power individuals would be more creative than low power individuals especially when creativity was functionally relevant to power. Moreover, we hypothesized that under unstable power this pattern would reverse, making low power individuals more creative than high power individuals when creativity was functionally relevant to power. These predictions were confirmed in Experiment 1. We further showed that under unstable power, low power individuals were more flexible thinkers than high power individuals, especially when creativity was relevant to power (Experiment 2). Finally, we found that under unstable power, low power individuals were less avoidant and had a global attentional focus compared to high power individuals, again, when creativity was relevant to power. A global attentional focus (but not reduced avoidance orientation or increased approach orientation) in turn led to higher creativity (Experiment 3). This research underscores the importance of the relevance of creativity to the goals and motives people have in a certain situation. In this research, people could show competence in exerting power by being creative. When the possibility existed to gain power -instead of the possibility of losing power- by being creative, this boosted creative performance, but only on those tasks that were functional to gaining power.

New research on power should take into account the importance of the stability of power positions. Most research on power assumes power positions are stable and secure, and 
no possibilities exist to loose the privileged position. Often, however, power positions are all but stable: managers leading international companies, dictators ruling a country, or leaders of a soccer team all face the possibility of losing their position. Once company results dramatically decline, support from the people collapses, or the game is lost once too often, leaders can be -and often are- replaced. Interestingly, one could presume that for low power individuals, power instability in itself is empowering, leading them to act and behave as high power individuals. Subjectively, they may feel as if they have high power in this situation. This is an interesting question future research could address.

Moreover, a more distal mediating mechanism for our findings may be that having unstable low power leads to feelings of confidence and self-efficacy, especially when low power individuals can gain power by being creative. They may be more confident about their abilities and also perceive that they have the 'power' to change their situation. Conversely, when high power individuals have the idea their power basis is disputed, they may perceive their actual level of power to be lower. Additionally, for high power people, instability of power creates unsafety and insecurity, which may narrow attentional focusing and lower creativity (Easterbrook, 1959). For low power people, instability of power and thus the possibility to gain power, may lead a broad attentional focus as a gain in power can concurrently lead to more safety and less dependency on others (Friedman \& Förster, 2010). In the paper by Kuhl and Kazen (2008), power was operationalized as a chronic personality motive. People with such a motive may be more afraid of losing power. This may explain why it was found that power leads to lower creativity. In Smith and Trope (2006) and Förster (2009), power was operationalized as "having power over others", which may have reminded people of situations in which they had relatively stable power over others.

A different but compatible mechanism may also explain the pattern of results that emerged. Recently, it has been suggested that the global information processing system is 
activated when people are confronted with novel information, but only when novelty is not potentially dangerous (Förster \& Dannenberg, 2010). Under instability of power, low power people see a beneficial potential for change, and this opens up a broader conceptual and perceptual scope. For high power people, however, novelty in this situation signals the possibility of losing their privileged position, is perceived as a threat, and leads to the activation of the local processing system - lo-sys (Easterbrook, 1959).

Whereas in the current experiments a change in the power hierarchy was not directly contingent on creative performance, new research could examine what happens when people lacking power can actually seize power by being creative. One possibility is that powerful individuals facing the risk of losing their position, are more prone to subversive and (c)overt aggression to secure their position, while low power individuals find creative ways of tackling problems, thereby coming into the picture and forwarding their interests. Moreover, under unstable power, powerful individuals may engage in deceit and plagiarize ideas of others they are competing with to forward their interests.

Perverse manifestations of power hierarchies come to mind quickly, such as domination and corruption, but hierarchy can create social order and coordination, and individual incentives to climb the ladder (Magee \& Galinsky, 2008). One interesting feature of power hierarchies is that they appear self-reinforcing; powerful individuals are more likely to act (Keltner, Gruenfeld \& Anderson, 2003; Galinsky, Gruenfeld \& Magee, 2003) use ideology, such as stereotyping (Jost \& Banaji, 1994) and legitimizing myths (Chen \& Tyler, 2001), choose those jobs that forward their interests (Pratto, Stallworth, Sidanius, \& Sears, 1997), and consequently, accumulate more resources and influence. Taken to its extreme, power hierarchies should result in a monopolistic 'winner takes all' power constellation (Magee \& Galinsky, 2008). We know that this is rarely the case; external changes, fairness and legitimacy and fierce competition over standing in the hierarchy can attenuate the self- 
reinforcing powers of hierarchies. Among those lacking power being creative may be another way to change the power hierarchy. When power positions are unstable, low power individuals are more flexible thinkers, are less avoidant and process information more globally. Consequently, they achieve more creative insights and generate more original thoughts, especially when being creative is relevant to (gain) power. As such, when the power hierarchy is unstable, those lacking power hold the power to creativity. 


\section{References}

Amabile, T.M., (1983). The social psychology of creativity: A componential conceptualization. Journal of Personality and Social psychology, 45, 357-376.

Baas, M., De Dreu, C.K.W., \& Nijstad, B.A. (2008). A meta-analysis of 25 years of research on mood and creativity: Hedonic tone, activation, or regulatory focus? Psychological Bulletin, 134, 779-806.

Bacharach, S.B., \& Lawler, E.J. (1981). Bargaining: Power, tactics, and outcomes. JosseyBass, San Francisco, CA.

Bruins, J. J. and Wilke, H. A. M. (1992). Cognitions and behaviour in a hierarchy: Mulder's power theory revisited. European Journal of Social Psychology, 22, 21-39.

Chen, E. S., \& Tyler, T. R. (2001). Cloaking power: Legitimizing myths and the psychology of the advantaged. In A. Y. Lee-Chai \& J Bargh (Eds.), The use and abuse of power: Multiple perspectives on the causes of corruption. Philadelphia: Psychology Press.

De Dreu, C.K.W., Baas, M., \& Nijstad, B.A. (2008). Hedonic tone and activation level in the mood-creativity link: Toward a dual pathway to creativity model. Journal of Personality and Social psychology, 94, 739- 756.

De Dreu, C.K.W., \& Nijstad, B.A. (2008). Mental set and creative thought in social conflict: Threat rigidity versus motivated focus. Journal of Personality and Social Psychology, 95, 648-661.

De Dreu, C.K.W., Nijstad, B.A., \& Baas, M. (2011). Behavioral activation links to creativity because it promotes cognitive flexibility. Social Psychological and Personality Science.

De Dreu, C. K. W., \& Van Kleef, G. A. (2004). The influence of power on the information search, impression formation, and demands in negotiation. Journal of Experimental Social Psychology, 40, 303-319. 
Diehl, M., \& Stroebe, W. (1987). Productivity loss in brainstorming groups: Toward the solution of a riddle. Journal of Personality and Social Psychology, 53, 497-509.

Easterbrook, J. A. (1959). The effect of emotion on cue utilization and the organization of behavior. Psychological Review, 66, 183-201. doi: 10.1037/h0047707.

Eisenberger, R., \& Rhoades, L. (2001). Incremental effects of rewards on creativity. Journal of Personality and Social Psychology, 81, 728-741.

Ekstrom, R. B., French, J. W., Harman, H. H., \& Dermen, D. (1976). Manual for kit of factor referenced cognitive tests. Princeton, NJ: Educational Testing Service Harkins.

Fiske, S. T. (1993). Social cognition and social perception. Annual Review of Psychology, 44, 155-194.

Förster, J. (2009). Relations between perceptual and conceptual scope: How global versus local processing fits a focus on similarity versus dissimilarity. Journal of Experimental Psychology: General, 138, 88-111.

Förster, J., \& Dannenberg, L. (2010). GLOMO sys: A systems account of global versus local processing. Psychological Inquiry, 21, 175-197.

Förster, J., Friedman, R., \& Liberman, N. (2004). Temporal construal effects on abstract and concrete thinking: Consequences for insight and creative cognition. Journal of Personality and Social Psychology, 87, 177-189.

Förster, J., Friedman, R. S., Özelsel,A.,\& Denzler, M. (2006). Enactment of approach and avoidance behavior influences the scope of perceptual and conceptual attention. Journal of Experimental Social Psychology, 42, 133-146.

Förster, J., \& Higgins, E.T. (2005). How global versus local perception fits regulatory focus. Psychological Science, 16, 631-636. 
French, J. R. P., \& Raven, B. (1959). The bases of social power. In D. Cartwright \& A. Zander (Eds.), Group dynamics (pp. 150-167). Ann Arbor, MI: University of Michigan Press.

Friedman, R.S., \& Förster, J. (2005). Effects of motivational cues on perceptual asymmetry: Implications for creativity and analytical problem solving. Journal of Personality and Social Psychology, 88, 263-275.

Friedman, R.S., \& Förster, J. (2001). The effects of promotion and prevention cues on creativity. Journal of Personality and Social Psychology, 81, 1001-1013.

Friedman, R. S., \& Förster, J. (2002). The influence of approach and avoidance motor actions on creative cognition. Journal of Experimental Social Psychology, 38, 41-55.

Friedman, R., \& Förster, J. (2010). Implicit affective cues and attentional tuning: An integrative review. Psychological Bulletin, 136, 875-893

Galinsky, A. D., Gruenfeld, D. H., \& Magee, J. C. (2003). From power to action. Journal of Personality and Social Psychology, 85, 453-466.

Galinsky, A.D., Magee, J.C., Gruenfeld, D.H., Whitson, J.A. \& Liljenquist, K.A. (2008). Power reduces the press of the situation: Implications for creativity, conformity, and dissonance. Journal of Personality and Social Psychology, 95, 1450-1466.

Georgesen, J., \& Harris, M.J. (2006). Holding onto power: Effects of powerholders' positional instability and expectancies on interactions with subordinates. European Journal of Social Psychology, 36, 451-468.

Griskevicius, V., Cialdini, R.B., \& Kenrick, D.T. (2006). Peacocks, Picasso, and parental investment: The effects of romantic motives on creativity. Journal of Personality and Social Psychology, 96, 63-76.

Guilford, J. P. (1950). Creativity. American Psychologist, 5, 444-454. 
Guinote, A. (2007a). Power affects basic cognition: Increased attentional inhibition and flexibility. Journal of Experimental Social Psychology, 43, 685-697.

Guinote, A. (2007b). Power and goal pursuit. Personality and Social Psychology Bulletin, 33, 1076-1087.

Handgraaf, M. J. J., Van Dijk, E., Vermunt, R. C., Wilke, H. A. M., \& De Dreu, C. K. W. (2008). Less power or powerless? Egocentric empathy gaps and the irony of having little versus no power in social decision making. Journal of Personality and Social Psychology, $95,1136-1149$.

Higgins, E. T. (1997). Beyond pleasure and pain. American Psychologist, 52, 1280-1300.

Kelley, H.H., \& Thibaut, J.W. (1978), Interpersonal relations: A theory of interdependence. New York: John Wiley \& Sons, Inc.

Keltner, D., Gruenfeld, D. H., \& Anderson, C. (2003). Power, approach, and inhibition. Psychological Review, 110, 265-284.

Kuhl, J., \& Kazen, M. (2008). Motivation, Affect, and Hemispheric Asymmetry: Power Versus Affiliation. Journal of Personality and Social Psychology, 95, 456-469.

Jost, J. T., \& Banaji, M. R. (1994). The role of stereotyping in system-justification and the production of false consciousness. British Journal of Social Psychology, 33, 1-27.

Lammers, J., Galinsky, A.D., Gordijn, E.H., \& Otten, S. (2008). Illegitimacy moderates the effects of power on approach. Psychological Science, 19, $558-564$.

Lee, F., \& Tiedens, L. Z. (2002). Is it lonely at the top? The independence and interdependence of power holders. In B. M. Staw \& R. I. Sutton (Eds.), Research in organizational behavior (Vol. 23, pp. 43-92). New York: JAI Press.

Leyens, J.P., Dardenne, B., \& Fiske, S.T. (1998). Why and under what circumstances is a hypothesis-consistent testing strategy preferred in interviews? British Journal of Social Psychology, 37, 259-274. 
Magee, J. C. \& Galinsky, A. D. (2008). Social hierarchy: The self-reinforcing nature of power and status. Academy of Management Annals, 2, 351-398.

Maner, J.K., Gaillot, M.T., Butz, D.A., \& Peruche, B.M. (2007). Power, risk, and the status quo: Does power promote riskier or more conservative decision making? Personality and Social Psychology Bulletin, 33, 451- 462.

Maslow, A.H. (1937). Dominance-feeling, behavior, and status. Psychological Review, 44, 404-429.

Mednick, M.T. (1962). The associative basis of the creative process. Psychological Review, $69,220-232$.

Mullen, B., Johnson, C., \& Salas, E. (1991). Productivity loss in brainstorming groups: A meta-analytic integration. Basic and Applied Social Psychology, 12, 3-23.

Muller, D., Judd, C. M., \& Yzerbyt, V. Y. (2005). When moderation is mediated and mediation is moderated. Journal of Personality and Social Psychology, 89, 852-863.

Navon, D. (1977). Forest before trees: The precedence of global features in visual perception. Cognitive Psychology, 9, 353-383.

Nijstad, B. A., De Dreu., C. K. W., Rietzschel, E. F., \& Baas, M. (2010). Towards a dualpathway to creativity model: Creative ideation as a function of flexibility and persistence. European Review of Social Psychology, 21, 34-77.

Nijstad, B.A., \& Stroebe, W. (2006). How the group affects the mind: A cognitive model of idea generation in groups. Personality and Social Psychology Review, 10, 186-213.

Osborn, A. F. (1953). Applied imagination. New York: Scribner.

Podsakoff, P., \& Schriesheim, C. (1985). Field studies of French and Raven's bases of power: Critique, reanalysis, and suggestions for future research. Psychological Bulletin, 97, 387411. 
Roskes, M., De Dreu, C.K.W., \& Nijstad, B.A. (2010). Overcoming the cognitive costs of creativity: When avoidance orientation stimulates creative ideation and insight. Unpublished manuscript, University of Amsterdam.

Pratto, F., Stallworth, L., Sidanius, J., \& Siers, B. (1997). The gender gap in occupational role attainment: A social dominance approach. Journal of Personality and Social Psychology, $72,37-53$.

Scheepers, D., \& Ellemers, N. (2008). When the pressure is up: The assessment of social identity threat in low and high status groups. Journal of Experimental Social Psychology, 41, 192-200.

Schwarz, N. , \& Bless, H. (1992). Constructing reality and its alternatives: Assimilation and contrast effects in social judgment. In L. L. Martin \& A. Tesser (Eds.), The construction of social judgment (pp. 217-245). Hillsdale, NJ: Lawrence Erlbaum Associates, Inc.

Smith, P. K., Jostmann, N.B., Galinsky, A. D., \& Van Dijk, W. W. (2008). Lacking Power Impairs Executive Functions. Psychological Science.

Smith, P. K., \& Trope, Y (2006). You focus on the forest when you're in charge of the trees: Power priming and abstract information processing. Journal of Personality and Social Psychology, 90, 578- 596.

Tajfel, H. (1984). Intergroup relations, social myths and social justice in social psychology. In H. Tajfel (Ed.), The social dimension: European developments in social psychology (Vol. 2, pp. 695-715). Cambridge, UK: Cambridge University Press.

Tetlock, P.E. (1981). Pre-to post-election shifts in presidential rhetoric: Impression management or cognitive adjustment. Journal of Personality and Social Psychology, 41, 207-212.

Torrance, E. P. (1966). Torrance tests of creative thinking. Princeton, NJ: Personnel Press. 
Van Kleef, G. A., De Dreu, C. K. W., Pietroni, D., \& Manstead, A. S. R. (2006). Power and emotion in negotiation: Power moderates the interpersonal effects of anger and happiness on concession making. European Journal of Social Psychology, 36, 557-581.

West, M.A., (2002). Sparkling fountains or stagnant ponds: An integrative model of creativity and innovation implementation in work groups. Applied Psychology: An International Review, 51, 355-424.

Willis, G.B., Guinote, A., \& Rodríguez-Bailón, R. (2009). Illegitimacy improves goal pursuit in powerless individuals. Journal of Experimental Social Psychology, 46, 416-419.

Yukl, G. A., \& Falbe, C. M. (1991). Influence tactics and objectives in upward, downward, and lateral influence attempts. Journal of Applied Psychology, 75, 132-140. 
Table 1

Processing style, avoidance motivation and creative insight as a function of unstable power and functional relevance (Experiment 3).

\begin{tabular}{lcccc}
\hline & \multicolumn{2}{c}{ Relevant } & \multicolumn{2}{c}{ Not relevant } \\
\cline { 2 - 5 } & High power & Low power & High power & Low power \\
\hline Creative insight & $7.85^{\mathrm{a}}(2.91)$ & $10.79^{\mathrm{b}}(3.02)$ & $9.29^{\mathrm{ab}}(2.64)$ & $9.00^{\mathrm{ab}}(3.21)$ \\
Processing style & $-.017^{\mathrm{a}}(.054)$ & $.027^{\mathrm{b}}(.064)$ & $.015^{\mathrm{ab}}(.050)$ & $-.009^{\mathrm{ab}}(.034)$ \\
Avoidance & $2.85^{\mathrm{a}}(1.21)$ & $1.86^{\mathrm{b}}(0.77)$ & $2.21^{\mathrm{ab}}(1.12)$ & $2.77^{\mathrm{ab}}(1.24)$ \\
\hline
\end{tabular}

Note. Means $(S D)$ with different superscripts in one row differ at $p<.05$ 


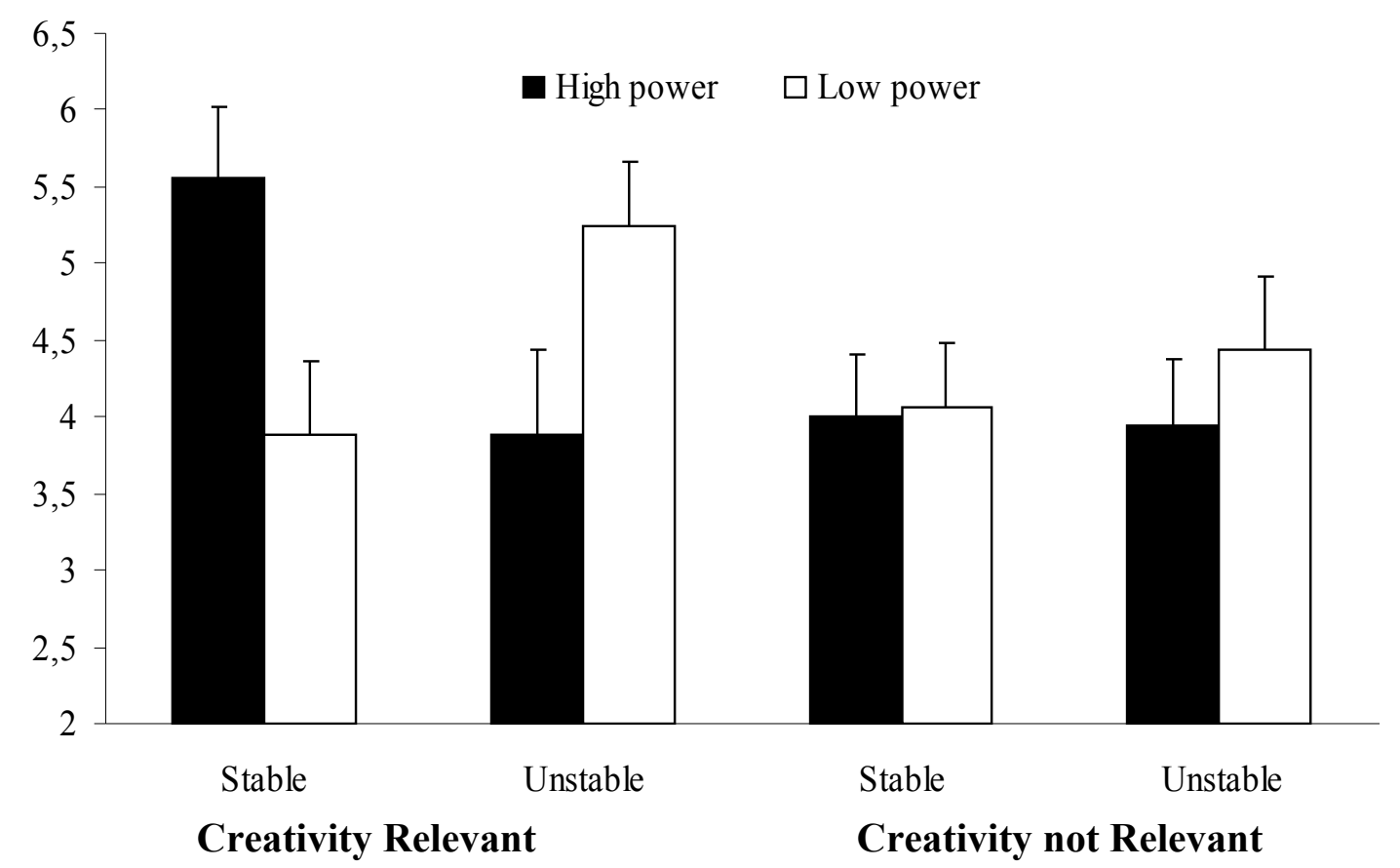

Figure 1. Creative insight as a function of power, stability and functional relevance (Experiment 1). Bars indicate +one standard error 


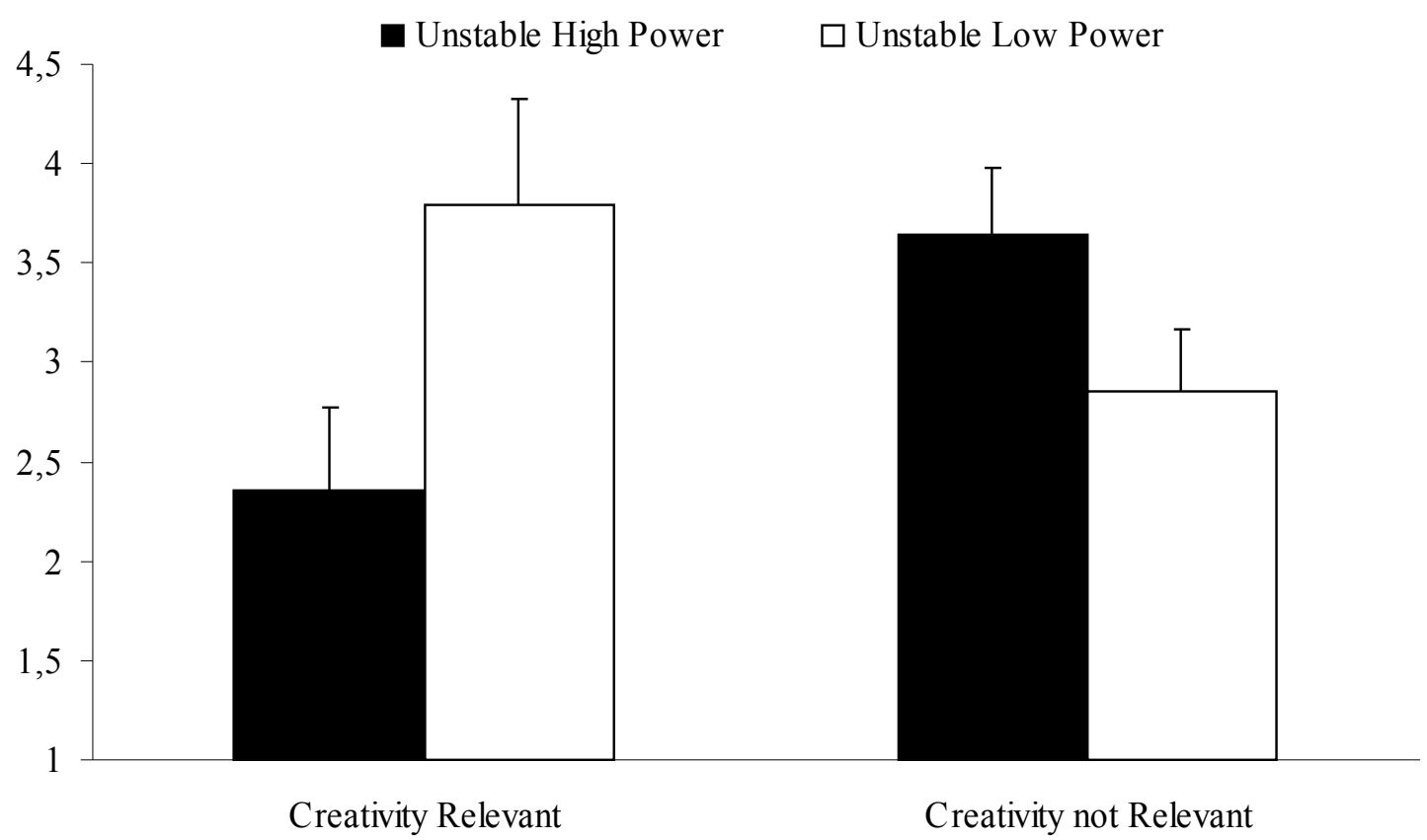

Figure 2. Cognitive flexibility as a function of unstable power and functional relevance (Experiment 2). Bars indicate +one standard error 


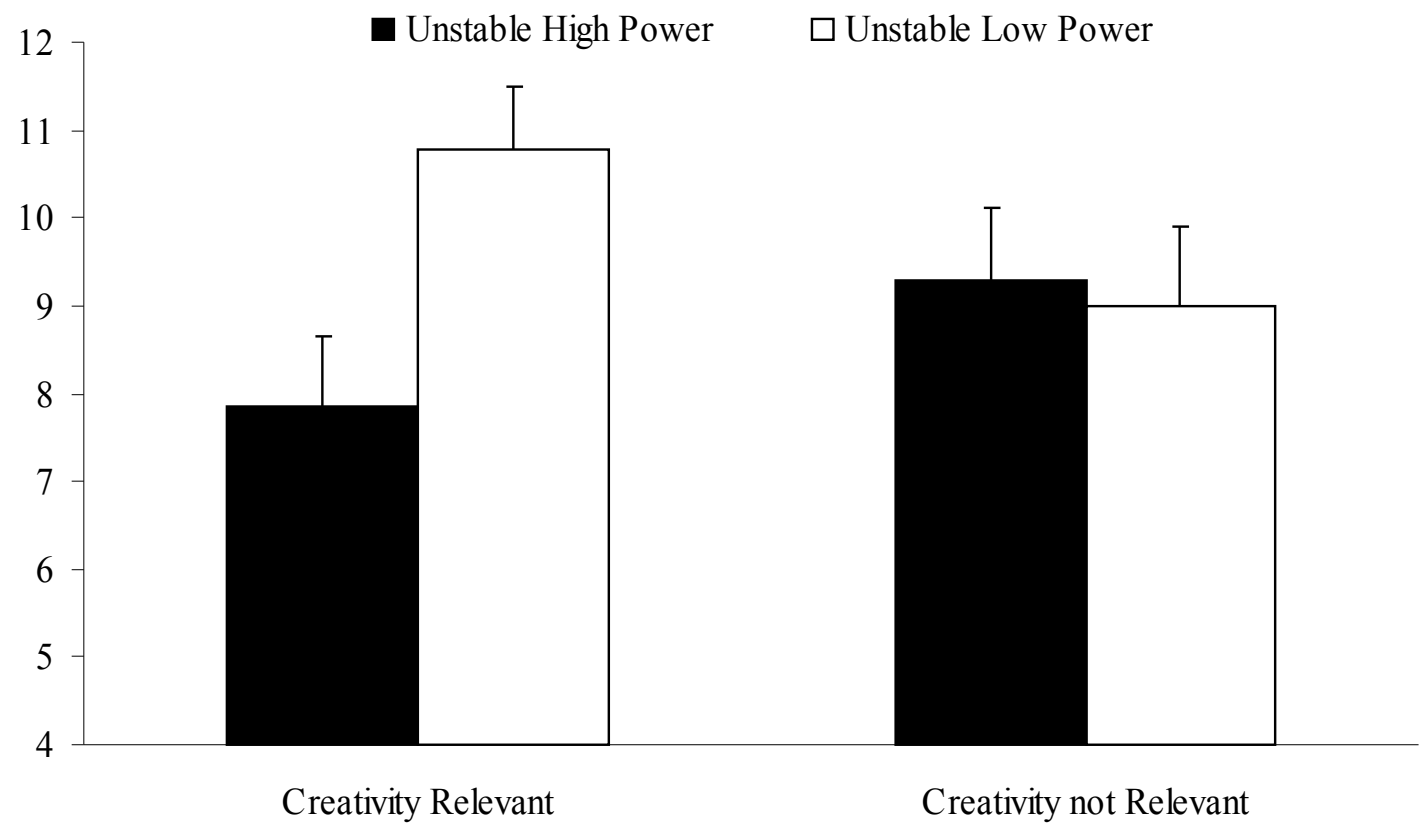

Figure 3. Creative insight as a function of unstable power and functional relevance (Experiment 3). Bars indicate +one standard error 


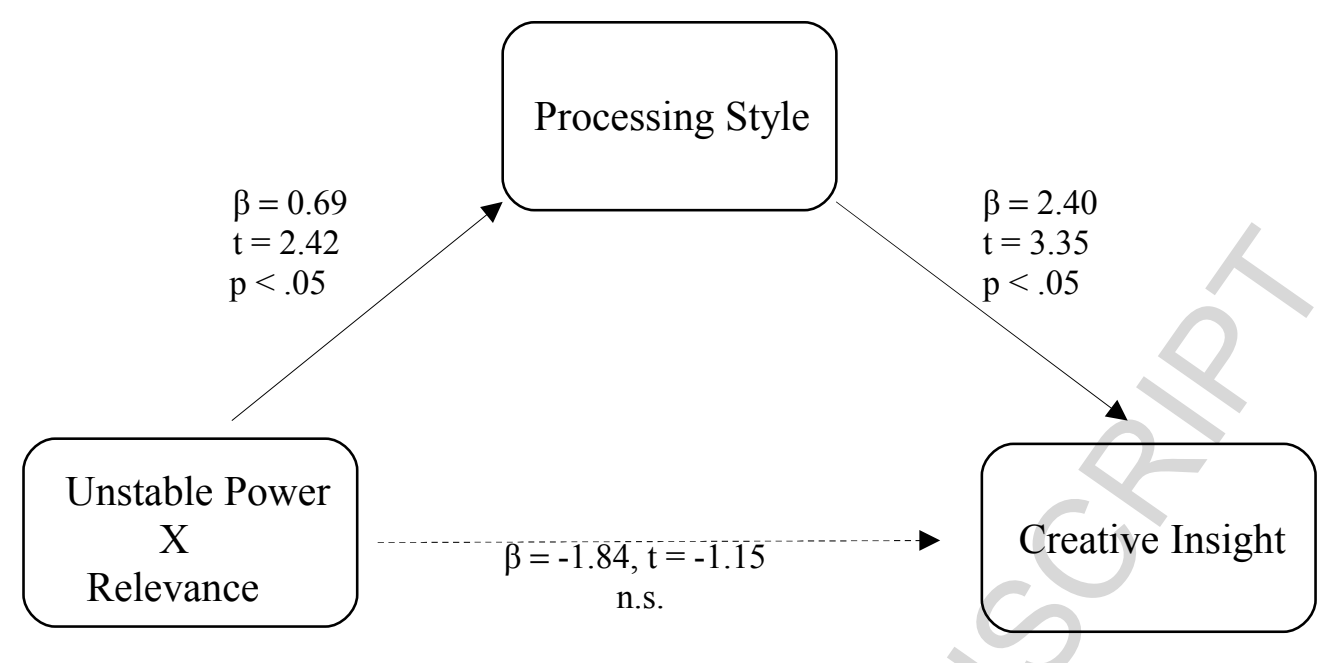

Figure 4. Effects of unstable power and functional relevance on creative insight are fully mediated by processing style (Experiment 3 ). $Z=1.99, \mathrm{p}<.05$. 